\title{
Editorial
}

\section{The medical and social model of childbirth}

\author{
Edwin Roland van Teijlingen * \\ Bournemouth University, Faculty of Health \& Social Sciences, Centre for Midwifery, Maternal \& Perinatal Health, \\ Bournemouth, UK
}

Sociologists and other social scientists can bring different perspectives and theoretical understandings to research into many common health topics. One of the specific contributions of sociology is that of two different models, a social model and a medical model of an illness and health. This editorial a) outlines the nature of the medical and social model; b) illustrates the two models using pregnancy and childbirth as an example; and c) stresses the importance of the application of these models in clinical practice.

\section{The medical model versus the social model}

In the late 19th century and early 20th century we have seen a rapid growth in science and medicine across the industrialised world. The growth coincided with a growing trust/popularity in rationalism and the idea that one day we will have discovered all laws of nature and society and be able to cure all diseases. These developments were accompanied by a growth in professions (in health as well as other occupations) and the rapid growth of hospitals as institutions. Health care professionals are socialised into thinking along the lines of a (bio)-medical model, a model largely based on physiology and biology which has a rather mechanical view of disease, illness and the human body. The disease is assumed to be in the patients, resulting in rather individualistic diagnosis and treatment. The medical model is 'easy' to understand, rational, based on medical science and diagnosis, and relies largely on objective measurement of symptoms and clinical observation. Thus the medical model offers individual treatment solutions for individual patients.
The social model argues that there is inter-dependency between the ill person and their immediate and wider environment. The social model focuses on everyday life and the social, socio-economic, cultural and environmental aspects of health. The social model considers a wider range of factors that affect someone's health; factors such as lifestyle, gender, poverty (or health inequality more generally), discrimination, and where and how we live. The disease is assumed to be part of the patients, caused, exacerbated or improved by the way they live their lives in their physical and socio-economic environment. The social model is generally not individualist, but complex and multi-dimensional and often does not offer easy solutions. Solutions to health problems can be found at a population level and hence can be political or social, as well as, for example, due to changes in the individual's lifestyle.

It is important to bear in mind that the medical and social model is not something static. We view a disease, impairment or a patient to be somewhere on a spectrum with a very social perspective at one end of the scale and a very medical one at the opposite end of that scale. The process of changing from a more social model to a more medical model is called medicalisation and the opposite is referred to as de-medicalisation.

\section{Childbirth as an example of the medical/social model}

The social model maintains that pregnancy and childbirth are largely physiological events that occur in most women's lives. Following this line of thinking, the social model

\footnotetext{
* Korespondenční autor: prof. Edwin Roland van Teijlingen, Bournemouth University, Faculty of Health \& Social Sciences, Centre for Midwifery, Maternal \& Perinatal Health, Bournemouth House, 19 Christchurch Road, Bournemouth, BU1 3LH, England, UK; e-mail: evteijlingen@bournemouth.ac.uk; http://dx.doi.org/10.1016/j.kontakt.2017.03.001
} 
argues that pregnancy and childbirth do not normally need medical intervention or the transfer to hospital. A social model of care accepts childbirth as a normal social event in which preventative measures can be used [1]. The medical model portrays a different view, namely that childbirth is potentially pathological, and therefore every woman is potentially at risk when she is pregnant and/or in labour. Again, following this line of thinking, every woman should deliver in hospital with high-technology screening equipment under the supervision of expert obstetricians. In other words, those following the medical model want to make us believe that pregnancy and childbirth are only safe in retrospect $[2,3]$.

\section{Why does it matter which model we adhere to?}

The first thing to remember is that the way we perceive or define 'the problem' also affects the kind of solutions we see and seek. For example, if we perceived obesity as a medical problem, we would look for the solution for overweight people in getting a gastric band fitted or using appetite-suppressing drugs. However, if we regard obesity from the perspective of a social model we may suggest that the solution lies in a sugar tax (to make sugary drinks and foods more expensive) or lifestyle changes at the community level.

This editorial highlights that someone's perspective of birth is not simply semantic. Thus, whether a midwife describes her role as being 'with woman' through labour or as someone who 'delivers' women of babies does not just demonstrate a more or less currently politically correct description. No, it suggests having different perspectives or world views of pregnancy and childbirth.

The claim by the dominant idea (ideology) that the medical model is the most appropriate and hence safest approach to pregnancy and childbirth not only controls women but also their families, their friends and their health care providers. This editorial argues that understanding the underlying sociological models of pregnancy and childbirth can help politicians, journalists, policy-makers, midwives, doctors, other health care providers, childbirth activists as well as pregnant women and new mothers (and their partners) to put the issues around 'normal birth' into perspective.

\section{REFERENCES}

[1] Ireland J, van Teijlingen ER. Normal birth: socialmedical model. The Practising Midwife 2013;16(11):1720.

[2] van Teijlingen ER. A critical analysis of the medical model as used in the study of pregnancy and childbirth. Sociol Res Online 2005;10(2). [online] [cit. 2017-02-21]. Available from: http://www.socresonline.org.uk/10/2/ teijlingen.html

[3] MacKenzie Bryers H, van Teijlingen ER. Risk, theory, social and medical models: a critical analysis of the concept of risk in maternity care. Midwifery 2010;26(5):488-96. 